\author{
Sebastian Kos \\ Rolf Huegli \\ Georg M. Bongartz \\ Augustinus L. Jacob \\ Deniz Bilecen
}

\section{MR-guided endovascular interventions: a comprehensive review on techniques and applications}

Received: 10 February 2007

Revised: 1 October 2007

Accepted: 30 October 2007

Published online: 11 December 2007

(C) European Society of Radiology 2007

\author{
S. Kos $(\bowtie) \cdot$ A. L. Jacob · D. Bilecen \\ Institute of Radiology, \\ Division of Interventional Radiology, \\ University Hospital Basel, \\ Petersgraben 4, \\ 4031 Basel, Switzerland \\ e-mail: skos@gmx.de \\ Tel.: +41-61-3286326 \\ Fax: +41-61-26555383 \\ R. Huegli \\ Institute of Radiology, \\ Kantonsspital Bruderholz, \\ Bruderholz, Switzerland
}

\author{
G. M. Bongartz \\ Institute of Radiology, \\ University Hospital Basel, \\ Petersgraben 4, \\ 4031 Basel, Switzerland
}

\begin{abstract}
The magnetic resonance (MR) guidance of endovascular interventions is probably one of the greatest challenges of clinical MR research. MR angiography is not only an imaging tool for the vasculature but can also simultaneously depict high tissue contrast, including the differentiation of the vascular wall and perivascular tissues, as well as vascular function. Several hurdles had to be overcome to allow MR guidance
\end{abstract}

for endovascular interventions. MR hardware and sequence design had to be developed to achieve acceptable patient access and to allow real-time or near real-time imaging. The development of interventional devices, both applicable and safe for MR imaging (MRI), was also mandatory. The subject of this review is to summarize the latest developments in real-time MRI hardware, MRI, visualization tools, interventional devices, endovascular tracking techniques, actual applications and safety issues.

Keywords Device tracking . Endovascular intervention · MR angiography $\cdot$ Real-time MRI

\section{Introduction}

An increasing demand for secure, minimally invasive interventional procedures has occurred in recent years. This is especially true for minimally invasive endovascular techniques developed for vessel stenosis and occlusion by percutaneous transluminal angioplasty (PTA), stenting or stent grafting. So far endovascular interventions are mostly performed under X-ray fluoroscopic guidance, where patients and staff are exposed to accumulating doses of radiation. Additionally, for sufficient intra-luminal contrast iodinated contrast agents are applied at cumulative doses, which may reveal relevant nephrotoxic effects. In contrast, interventional magnetic resonance imaging (iMRI) has no known harmful effects as it avoids radiation exposure. Additionally, the injection of gadolinium-based contrast agents is normally restricted to much lower doses with respective lower nephrotoxicity. MRI also provides superior soft tissue contrast, sufficient high spatial resolution and allows multiplanar three-dimensional reconstructions or maximum intensity projections. In addition, functional parameters like flow, temperature, tissue oxygenation, perfusion and diffusion can also be visualized and might influence the end-point of an endovascular intervention in the near future [1]. Because of this, MRI is a valuable tool for endovascular procedures [2-7].

The first part of this review article addresses technical developments. The MRI hardware and MR visualization tools and the essentials of MR angiography are presented. Interventional devices and endovascular tracking techniques are summarized. In the second part, an overview on the actual applications is given and tools for intravascular interventions and a preview on future developments are described. Resulting safety issues are addressed. 


\section{MRI hardware and visualization tools}

The optimal configuration of an MR system for interventional procedures provides three key features. (1) Free patient access, in combination with (2) fast MR data acquisition and (3) a high image quality. In reality interventional imaging is a trade-off between patient access, field of view, signal-to-noise ratio (SNR) and costs.

Since both the spatial and temporal resolution of MR images depend directly or indirectly on the magnetic field strength, higher $\mathrm{B}_{0}$ fields are more suited; but, on the other hand, the large magnets necessary disturb the accessibility of the patient. Also, the gradient systems need to become stronger and faster to increase the data acquisition and SNR. Limitations of this development might be physiological effects, like tissue heating and nerval stimulation [8].

Different MR scanners are in use for interventional procedures, as (1) open scanner (Fig. 1a), (2) short-bore scanner (Fig. 1b) and (3) hybrid systems (Fig. 1c,d). Regarding the open MR systems, variant designs are presently available in order to gain better patient access compared with standard diagnostic "closed" MR scanners (Fig. 1). For example C-shaped systems with a vertically oriented magnetic field are frequently used for biopsies and thermal ablations (Fig. 1a) [9]. These MR systems allow better patient access (e.g. lateral, foot, head). However, they lack a sufficient SNR and imaging speed as they use weaker magnetic fields and lower gradient strength $\left(\mathrm{B}_{0} \leq\right.$ $1 \mathrm{~T}$, slew rate $50 \mathrm{~T} / \mathrm{m} / \mathrm{s}, \mathrm{G}_{\max } \leq 25 \mathrm{mT} / \mathrm{m}$ ) compared with standard MRI $\left(B_{0} \geq 1.5 \mathrm{~T}\right.$, slew rate $100 \mathrm{~T} / \mathrm{m} / \mathrm{s}, \mathrm{G}_{\max } \geq$ $30 \mathrm{mT} / \mathrm{m})$. For exemple, the use of a 1-T closed-bore scanner halved the procedure time when guiding percutaneous angioplasty in swines compared with a $0.2-\mathrm{T}$ openbore system [10]. As SNR and speed are essential for MR endovascular procedure control and steering, those open systems are presently not well suited for these procedures.

In contrast to percutaneous biopsies and thermal ablations, routine endovascular interventions allow a distance between the puncture site and the target region. Therefore, common MR scanners may be acceptable for endovascular interventions in certain cases with the puncture site outside the scanner and the area of interest in the iso-centre of the magnet. However, to serve practical interventional needs, such systems have already been modified, now providing shorter magnets $(125 \mathrm{~cm}$, commonly $160 \mathrm{~cm})$ with a larger gantry diameter $(70 \mathrm{~cm}$, commonly $60 \mathrm{~cm}$ ) (Fig. 1b). Thereby patient access is further improved at the expense of a smaller field of view (35 cm, commonly $50 \mathrm{~cm}$ in z-direction).

Keeping the peri-interventional switch to conventional fluoroscopy guidance an option, XMR systems have been developed and are in use, combining MR system and conventional angiography $[11,12]$. Different designs are available on the market, with either the X-ray source between two halves of a magnet (so-called double dough$n u t)$ or keeping both systems separate connected by a patient transport lane (Fig. 1c,d) [13-15]. The first alternative avoids delays by patient transport, the latter keeps the option to use both methods independently.

Beside the innovations in the MR design, it is crucial to increase the interactive capabilities of the system. The interventionalist needs tableside control to trigger sequences without a relevant delay. Real-time availability with inter-
Fig. 1 Different designs of interventional MR systems. a A 1.0 -T vertically oriented magnet, allowing patient access from head, foot, and from the side. b A short $(125 \mathrm{~cm}) 1.5-\mathrm{T}$ magnet with a $70-\mathrm{cm}$ opening allowing transfemoral vessel access. c, d Hybrid system connecting MRI (c) and DSA (d) via a transport lane. (Courtesy of Philips, Hamburg and Siemens, Munich)

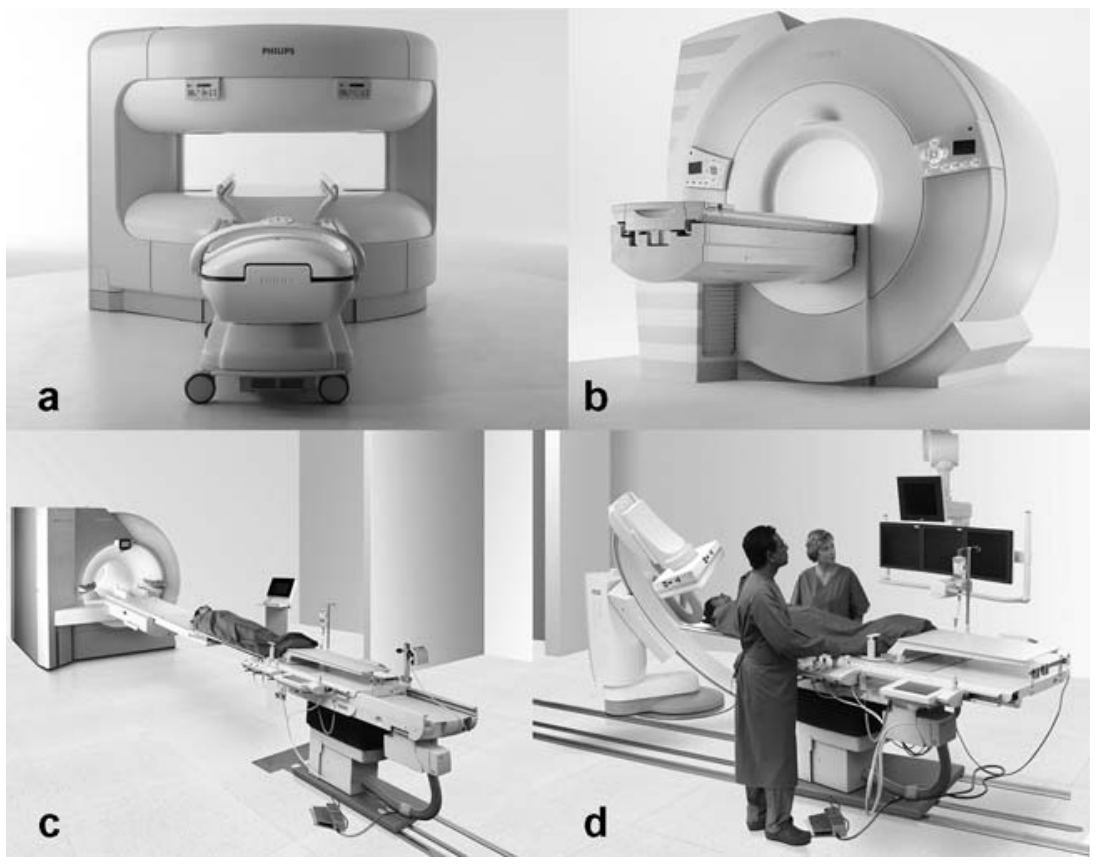


active data transfer of acquired MR images is mandatory, with in-room projection devices already in use [16].

\section{Essentials of MR angiography in endovascular interventions}

In combination with X-ray fluoroscopy-guided interventions, intra-arterial digital subtraction angiography (DSA) is still the "gold standard" of diagnostic angiography. Lacking exposure to iodinated contrast media and ionizing radiation, MR angiography has nevertheless been shown to accurately depict the anatomy of vessels and its pathologies as seen in peripheral artery occlusion disease (Fig. 2) [17, 18]. Additional to projective images, MR angiography offers three-dimensional (3D) imaging that exceeds the capabilities of the standard method DSA. By this, not only various reconstruction methods (MPR) can be applied, like maximum intensity projection (MIP), and surface rendering options but it also offers direct access to the morphology of the vascular wall [19]. Thereby the status of the vessel wall can be assessed and furthermore even the balloon can be depicted during the PTA (Fig. 3).

Of course, vessel depiction and access is possible with native MR sequences (e.g. SSFP sequences) only, which was widely used in interventional animal studies [20,21]. However, for most clinical procedures, the application of

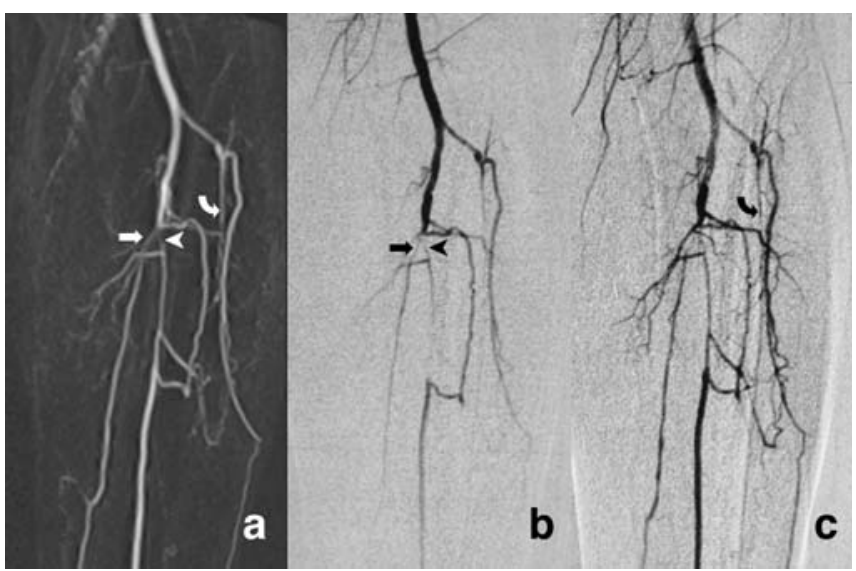

Fig. 2 Comparison between MR angiography and DSA in a 65year-old woman with known peripheral arterial occlusive disease and left-sided lower leg claudication. Angiographies reveal a significant stenosis at the origin of peroneal (arrowhead) and posterior tibial (straight arrow) arteries. Collateralization extends from the tibioperoneal trunk to the peroneal artery and fades with vessel occlusion in the descending part of the anterior tibial artery (curved arrow). a Coronal MIP of a mask-subtracted 3D gradientecho image of the proximal calf arteries acquired with intra-arterial MR angiography (3.5/1.3; flip angle, $20^{\circ}$; matrix, $448 \times 307$; field of view, $380 \times 326$; voxel size, $0.8 \times 1.1 \times 1.0 \mathrm{~mm}$; acquisition time, $33 \mathbf{s}$ ). b, c Corresponding intra-arterial DSA images obtained in the early (b) and late (c) phases of the examination. (Reproduced from Huegli et al. [17])

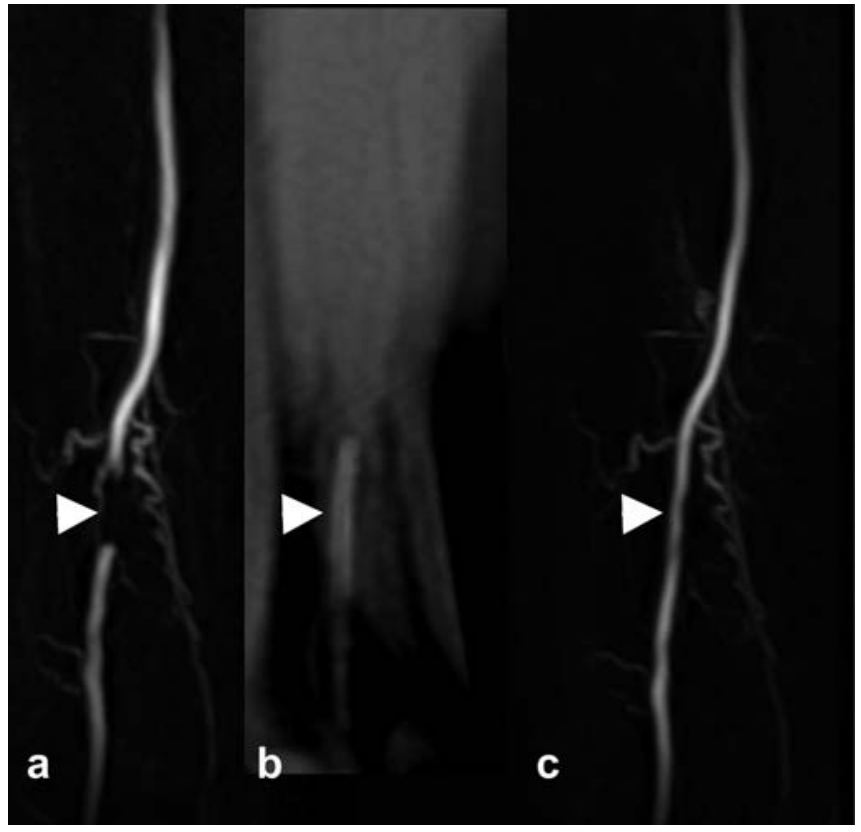

Fig. 3 Intra-arterial MR angiography in a patient with peripheral artery occlusive disease (PAOD) before (a), during (b) and after (c) dilatation of the femoro-popliteal artery. Arrowheads mark a short occlusion of the distal superficial femoral artery (a), the endovascular balloon-catheter in place (b) and the result after dilatation (c)

MR contrast media is helpful [22]. This increases the blood contrast and provides excellent angiograms, but may also assist precise device tracking. Furthermore, contrast media can provide grading of stenotic lesions and might depict active extravasation of contrast media during acute bleeding. Contrast images (3D MR angiography) may even be used as a template for later contrast-enhanced roadmap and/or overlay techniques [18].

Compared with intravenous MR angiography, a substantial reduction of the injected gadolinium dosage during interventional procedures can be achieved by intra-arterial injection using the side port of the introducer sheath or a selective catheter in place, without loss of image quality [17]. Presently the intra-arterial application of gadolinium is an off-label use, which may be applied as there are no serious side effects documented so far. Due to the short half-life of gadolinium chelates and the consecutive need for repetitive applications, a low-dose gadolinium injection protocol is required $[18,23]$. Herein, multiple applications of gadolinium chelates during interventions should not exceed the daily dose limit $(0.3 \mathrm{mmol} / \mathrm{l} / \mathrm{kg}$ body weight $)$ for gadolinium, as given by the U.S. Food and Drug Administration (FDA). The previously suggested injection protocol, depending on factors like injection rate, blood flow rate of the target vessel and gadolinium concentration, furthermore keeps the gadolinium blood concentration in a target range during MR data acquisition [23]. This is important because the paramagnetic effects of gadolinium 
would otherwise lead to fast spin-dephasing with T2/T2* signal reduction (gadolinium concentration above target range) or signal loss due to insufficient T1-shortening (gadolinium concentration below target range) [24].

Blood pool contrast agents like Gadomer-17 allow a longer vessel detection and prevent flow artefacts during catheter manipulation as the steady state is reached earlier. For catheter detection additive catheter injections of a negative contrast medium $\left(\mathrm{CO}_{2}\right)$ as a double-contrast technique were applied. Resulting replacement of the Gadomer-enhanced blood at the catheter tip and consecutive immediate temporal signal loss in the vessel lumen improved catheter visibility in one study [25]. The same might be true for Vasovist as the presently only certified blood-pool contrast agent on the market [26].

In vivo, MR angiography-guided angioplasty in swine was also performed with intra-arterial contrast medium application. Omary et al. [27] depicted the aortorenal vasculature prior to the procedure by injecting gadopentate dimeglumine at $4 \mathrm{ml} / \mathrm{s}$ using an aortic catheter. After dilatation of the surgically induced renal artery stenosis, the same group documented the technical success with another catheter-directed intra-arterial contrast-enhanced MR angiography. Overall, the definite indication for contrast media application is presently not clear but it certainly may play a major role in endovascular interventions in humans.

In contrast to standard diagnostic MR imaging, iMRI shifts the balance from spatial to temporal resolution. For near real-time imaging the lower limits of the image quality are defined by the ability to track endovascular devices [28].

Conventional contrast-enhanced MR angiography sequences are based on repetitive application of a fast
T1-weighted FLASH sequence, well usable for 3D angiographies, but its use for device tracking is limited by partial volume effects along the slice direction [29-31].

Better suited for device tracking in endovascular interventions are gradient imaging techniques [steady-state fast precession (SSFP) techniques, TrueFISP, FIESTA or balanced fast field echo], which in combination with contrast enhancement provide a high SNR and increased speed with a short TR, allow improved projection of vessels and its surrounding tissue with high signal and contrast $[32,33]$.

Therefore intra-arterial gadolinium-enhanced images are subtracted from a native background mask gained by averaged consecutive SSFP measurements (Fig. 4). In contrast, non-balanced SSFP techniques show a slightly lower signal intensity than balanced SSFPs but are more robust and less vulnerable to influences like flow or motion artefacts, eddy currents and imperfect shim [34]. After acquisition of native mask images, used for background suppression, intra-arterial filling images are added to create a road map image to guide further interventions. Acceleration of the image acquisition is achieved by parallel acquisition techniques with generalized autocalibrating partially parallel acquisition (GRAPPA) [35], and key-hole imaging [36]. GRAPPA algorithm with an acceleration factor of 2 was able to reduce the acquisition time per image by $34 \%$ in an approach with active catheter racking and automated slice alignement [21]. Thereby the catheter was steered from the inferior vena cava through the beating heart into the pulmonary vasculature. Recently Potthast et al. used parallel acquisition techniques (GRAPPA) in MR aortography [37]. Being initially developed to monitor the effect of contrast agents, by 1997 the keyhole technique had speeded up MR catheter tracking by a factor of $4[20,36]$.
Fig. 4 Complex subtracted intra-arterial near real-time contrast-enhanced MRI of the superficial femoral artery in a patient with peripheral artery occlusive disease. This MR fluoroscopic technique allows data acquisition times of $700 \mathrm{~ms}$ per frame

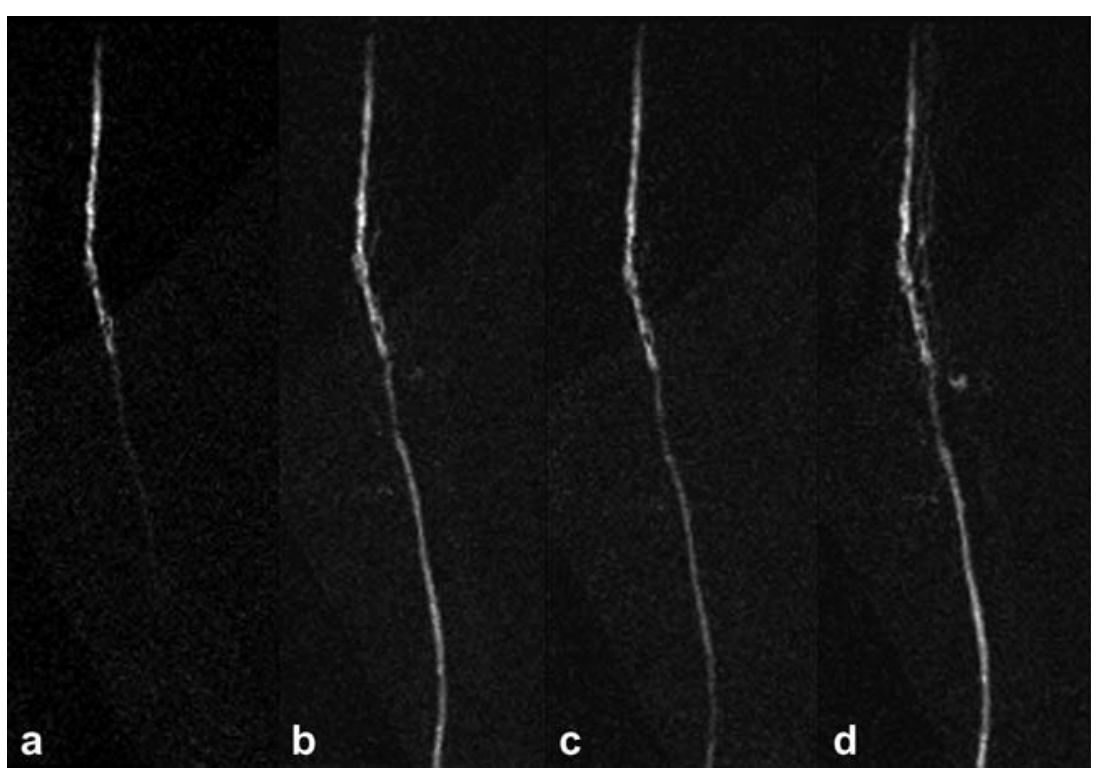




\section{MRI device-tracking techniques}

Respecting the interventionalist's needs when performing endovascular procedures, the techniques applied should be maximally robust, as simple as possible, and cost-effective. In iMRI the tools used for conventional X-ray fluoroscopyguided interventions are either almost invisible (e.g. plastic catheters), cause severe artefacts like metallic implants or metal-enforced catheters, or are unsafe (e.g. metallic guidewires may induce heat). Today two principle strategies in iMRI device development are under evaluation and seem to be valuable. These strategies can be subdivided into a "passive" and an "active" visualization approach, each having its specific advantages and limitations (Fig. 5) $[6,38]$.

Concerning the "passive" approach susceptibility markers (negative markers) for guidewires or signal enhancing markers (positive markers) for guidewires and catheters are linked to the device, thereby gaining detectability as a key feature without using further hardware $[6,7]$.

As positive markers, paramagnetic contrast media have been applied either on the surface of the catheter or within its lumen, in combination with T1-weighted sequences [39]. As negative markers, creating local field distortions, paramagnetic rings or ferrite-mixtures are in use. Small markers can be mounted on non-conducting (e.g. plastic) guidewires and catheters, allowing sufficient negative contrast under in vivo conditions $[20,40]$. As a disadvantage, those negative markers creating susceptibility artefacts may be masked by other signal losses within the excited slice, e.g. by metallic implants, calcifications or bowel air.

\section{MR tracking techniques}
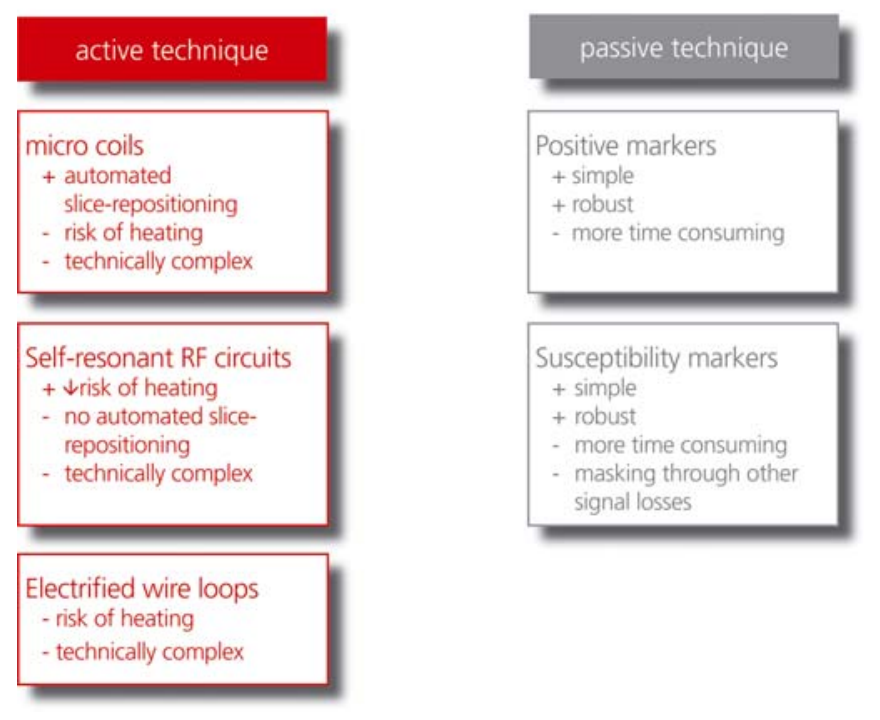

Fig. 5 Synopsis of different active and passive tracking techniques, with its specific advantages $(+)$ and limitations $(-)$
Endovascular devices must provide a high flexibility to adapt to the individual vessel configuration during navigation, as many arteries, such as the iliac arteries, have kinks and curves. This means that in most of the cases they are not depictable in a single thin slice and thick slabs are needed to depict vessel anatomy. But as a dilemma, to increase the contrast between the susceptibility artefact and the surrounding tissue it is necessary to keep the slicethickness as thin as possible and to use image subtraction from a baseline image to highlight the signal changes invoked by the device [41]. Those subtracted images can be overlaid on a contrast-enhanced roadmap MR angiogram, as mentioned above. As a limitation, the susceptibilityinduced passive tracking schemes using image subtraction showed a lack of consistency in device visualization, due to the influence of different field-strengths, motion, device orientation, device material and sequence parameters on the artefact [42-44]. The use of an adaptive subtraction technique, which automatically selects the most suitable reference image from a dynamic series for subtraction, was described by Bakker et al. in 2004 [45]. This leads to a reduced image vulnerability to slow periodic motion (e.g. breathing), only transient degradation by gross subject motion or alternation of the scan parameters and thereby a more robust and consistent depiction of the artefact. To allow monitoring of the catheter tip and shaft simultaneously, projection techniques in combination with a background suppression technique have been suggested [45-47].

Omary et al. [46] applied mask-mode subtraction to increase catheter visibility and a projection dephaser in the slice-selection direction to suppress background signal. Thereby they increased the contrast between background and catheter and were able to depict the catheter on its entire length when showing the feasibility of renal artery angioplasty in a pig model.

A relevant drawback of passive tracking versus the active approach may be found in the fact that passive tracking is image-based and thus, automated slice-repositioning not yet feasible. Therefore, a manual repositioning of the slice might be more time consuming. This may be compensated as in combination with the previously described fast sequences and applying projection techniques, key-hole imaging, and parallel imaging, near real-time imaging can be achieved with appropriate image quality, spatial resolution and field of view.

However, a major and crucial advantage is that, unlike the active tracking techniques in use, passive tracking techniques are much more simple to use and more robust, thereby fulfilling key features for interventional procedures [6].

Active tracking was introduced by Dumoulin et al. in 1993 [48]. The active tracking approaches available as (1) micro coils, (2) electrified wire loops and (3) self-resonant radiofrequency circuits, use active signal detection or extinction by the device as the common feature [49]. 
As the underlying principle using micro coils, a nonselective radiofrequency pulse emitted by a transmitting coil (e.g. surface body coil) leads to a peak in Fourier transformed signals, when detected by radiofrequency micro-receiver coils mounted on the device. Using low flip angle amplification, the signal of spins in close proximity to the catheter coil appears bright due to the resonance in the coils, whereas the surrounding tissue has a low signal intensity [50].

By gradient readouts along a single axis, the position can be fast determined $[49,51,52]$. By repetition along the other axes, the precise $3 \mathrm{D}$ position of the device can be determined within three repetition times. As an advantage, image acquisition is not necessary and the detected device position can be superimposed on a prior generated, e.g. contrast-enhanced roadmap image or a real-time image acquired intermittently $[53,54]$. Consecutively, automated scan plane and parameter adjustments based on the current device position are possible $[55,56]$. This means that active tracking is less time consuming regarding device tracking in complex vessel configurations, compared with the passive approach.

The coils are mounted either only on the tip of a catheter or along the whole catheter axis to track both tip and shaft, with each coil connected to a separate receiver channel [51]. Arrays with a single receiver coil display a single point of the catheter on the background image, giving no information on the orientation and configuration of the device, as a major drawback for endovascular interventions. Multiple coils along the device axis allow separate visualization of the different coils, which can be encoded in different colours on the roadmap image, but again increase the technical effort significantly. Variant configurations, to gain detectability of the whole device, with a coil at the tip and a guidewire antenna in the core of the catheter (socalled profiling) have been described $[48,57]$.

As major disadvantages of active tracking with microcoils, (1) sophisticated synchronization with external tuning, matching and decoupling electronics is needed, consecutively raising (2) the product costs. Therefore a direct cable connection (e.g. coaxial cable or laser fibres) between these electronics and the device is used. With the long conducting wire in situ, the radiofrequency energy which is transmitted into the body might get locally amplified and thus (3) may lead to rapid radiofrequency heating in vivo [57]. The latter risk can be reduced by integrating, for example, transformers or coaxial chokes into the cable between scanner and device, but this again increases the technical effort significantly $[58,59]$.

The use of micro-coils under in vivo conditions reveals robust tracking of the catheter tip and has been successfully demonstrated in animal models (Fig. 6). Wacker et al. [56] presented a so-named catheter-driven MRI scanner, which collects the tracking data within $40 \mathrm{~ms}$, needs another 10$20 \mathrm{~ms}$ for localization and image updates, and is thereby able to localize a motionless catheter equipped with micro- coils in the aorta in $100 \%$ of the cases and a moving catheter in $98 \%$ of the attempts. Automated consecutive real-time adjustments of spatial resolution and field of view respecting the catheter velocity allowed successful catheterization of renal arteries in two pigs. Bücker et al. [60] were able to guide and position a balloon catheter into a surgically created porcine arterial stenosis using a microcoil on a catheter tip and simultaneously acquire real-time (20 frames/s) vascular visualization with a radial gradient echo technique. Bock et al. [54] used 5-French catheters equipped with three separate radiofrequency coils at a distance of $3 \mathrm{~cm}$, for successful navigation of a catheter into the aorta and renal arteries of a pig.

As another active tracking approach, controlled focal distorsions of the magnetic field have been induced by a small direct current (10-150 mA) applied through an electrified wire loop in a catheter. This is comparable to the passive tracking methods leading to intravoxel dephasing and consecutive signal loss in the vicinity of the device [57]. Until today with this technique device localization in vivo is not feasible.

Trying to minimize the risk of rapid heating in vivo, a strategy based on self-resonant radiofrequency circuits, which in earlier MR research were successfully employed as high-contrast localization markers, was developed [50]. For this purpose, a coil or antenna tuned to the Lamor frequency of the scanner is attached to the catheter, connecting the MR signal to the surface coil via induction and making a direct cable connection unnecessary (Fig. 7) [61]. Thereby, Quick et al. [61] demonstrated high contrast visualization of a long catheter segment including curvature and tip in the aorta of a swine (Fig. 8). As a drawback, this method does not allow automated slice-repositioning and is rather sensitive to detuning. Furthermore, the lack of a direct connection to the MR system, decreasing the risk of rapid heating, leads to a constant flip angle amplification even in intermittent imaging, which may cause artefacts in the vicinity of the device. This again can be overcome by adding a photo-resistance, changing the resonance-circuit using light from an optical fibre [62], thereby again increasing the technical effort.

As prototypes, the detection of gradients-fields using Hall probes or a Farraday sensor were presented and are mentioned here only for the sake of completeness, with in vivo test not being performed yet $[63,64]$.

We must emphasize that the active and passive tracking techniques may well be used simultaneously. If radiofrequency heating is not crucial or can be limited as described above, a combination of tracking techniques may allow distinction of different instruments used during endovascular procedures. In an animal study, an actively tracked 0.030 -inch diameter loopless antenna guidewire coil, in combination with a passively tracked 5 -French aortic cathteter filled with dilute $4 \%$ gadopentate dimeglumine, allowed catheterization and stenting of renal arteries [27]. 

quired with five imaging coils and an active imaging coil at the catheter tip. The tracking coli is either visible as a bright spot (open arrows) or the coil position is marked by a dotted cross (a, d, g). The catheter is advanced through the vena cava $(\mathbf{a}, \mathbf{b})$ into the right atrium $(\mathbf{c}, \mathbf{d})$ and right ventricle $(\mathbf{e}-\mathbf{g})$, and further into the pulmonary artery (h). (Reproduced from Bock et al. [21])
Fig. 6 Real-time TrueFisp ac-
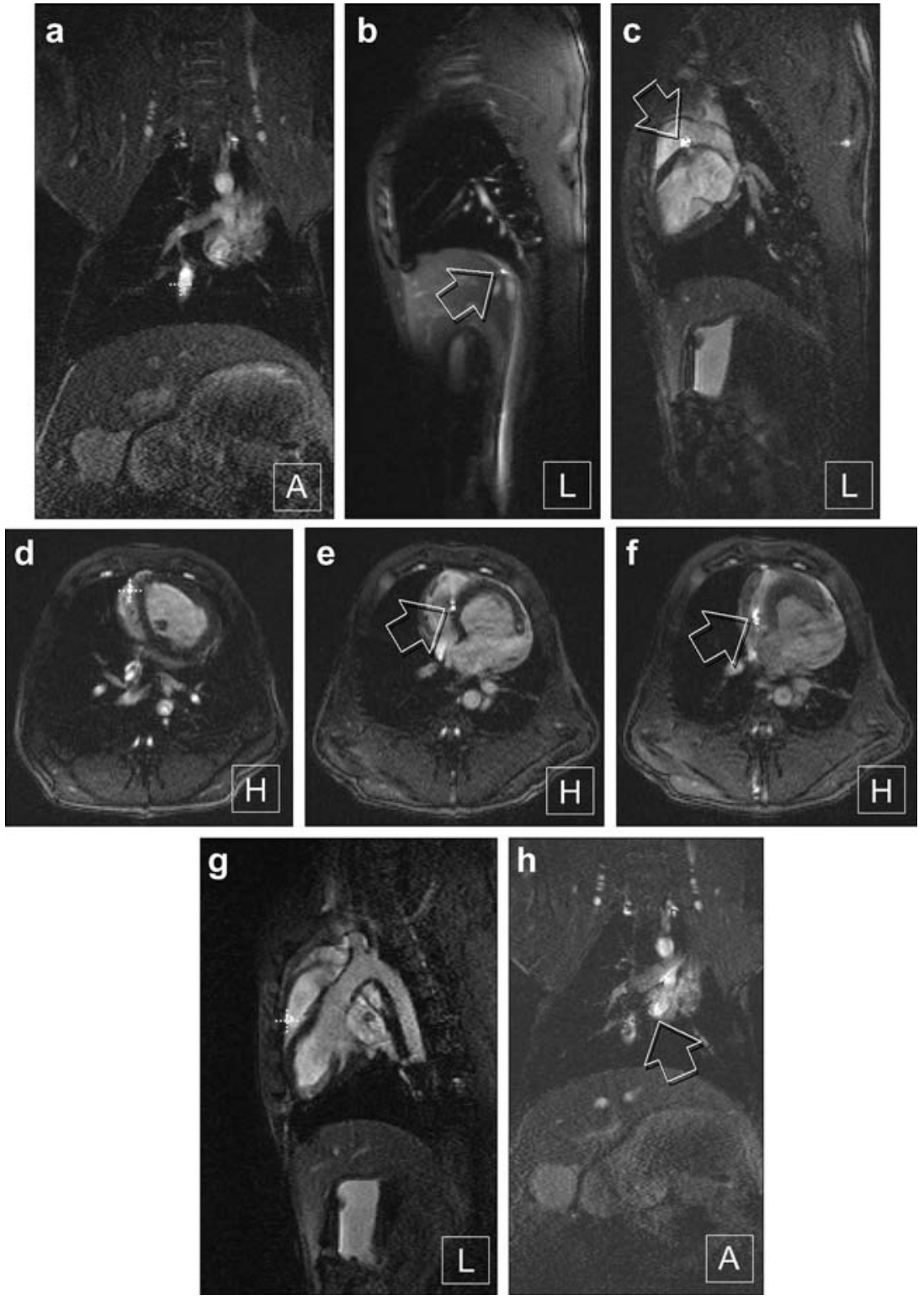

\section{New interventional devices}

A crucial step in the future evolution of iMRI will be the further development and evolution of diagnostic catheters, guidewires, stents and other interventional tools, which need to be compatible, safe, visible, robust and as simple and cheap as possible.

In 1997, Bakker et al. [20] were the first to use the passive tracking technique for catheter localization and steering in the basilic vein of a human. At this time, dysprosium markers mounted on a 3-French non-braided catheter were $1-\mathrm{mm}$ thick and coated by a $0.1-\mathrm{mm}$ thick nylon sleeve, thereby increasing the catheter diameter and reducing potential access to smaller vessels siginificantly. This clearly demonstrates that tracking techniques and devices must be developed in parallel if they should not inhibit the others progression.

A huge step has been made by presenting MR-compatible 0.035 -inch diameter guidewires using fibreglass [65] or a polyetherketone (PEEK) (Fig. 9). This was necessary as standard guidewires with a stainless steel core may be drawn into the magnet, nitinol guidewires may lead to rapid heating as discussed below and simple plastic guidewires are too floppy and lack satisfactory torque control [6].

The PEEK-guidewire presented by Mekle et al. [40], consists of a PEEK polymer core, with a conic shape at its flexible distal end, where it's coated with small iron particles. Even with the additional outer polymer coating, the diameter is only 0.035 inch over the entire length of the wire, thereby reducing influences on the mechanical 
a Loop surface coil

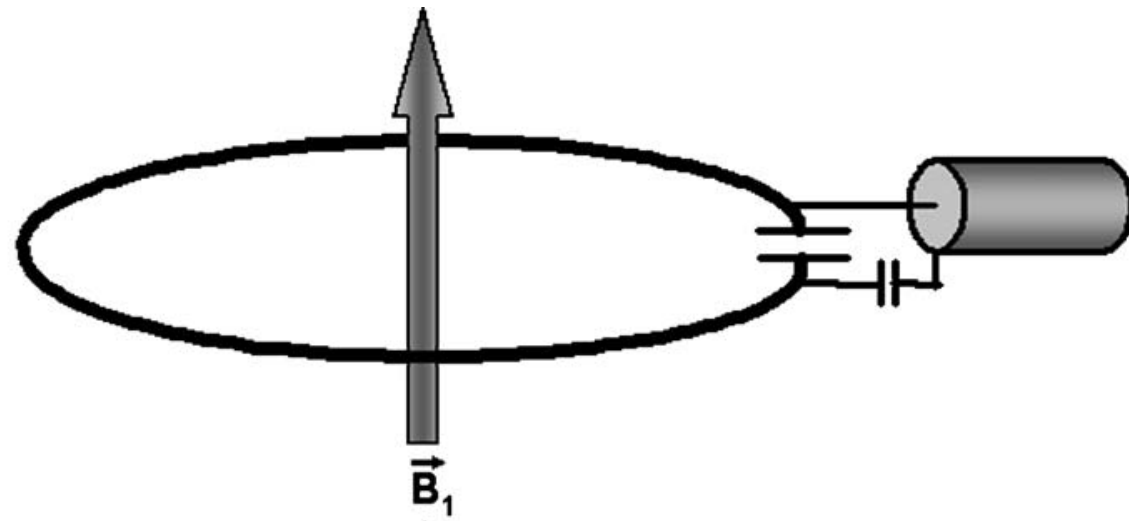

to receiver

distal end of catheter

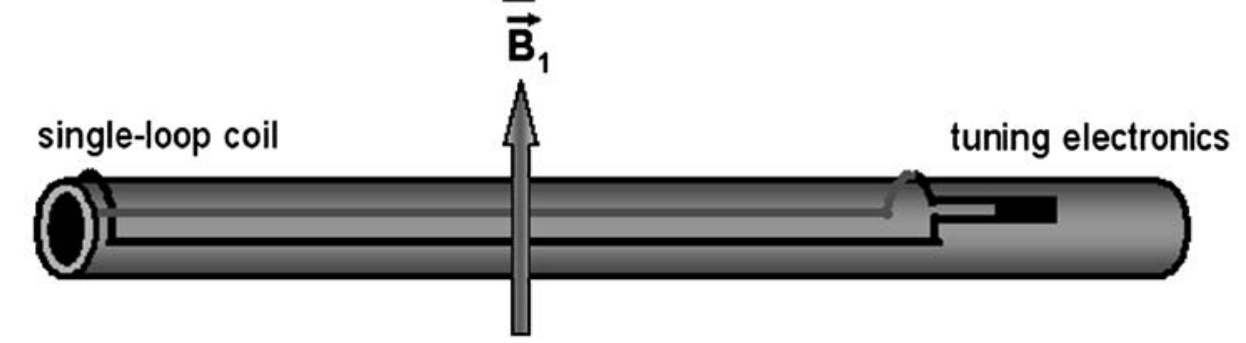

\section{b Catheter-mounted inductively coupled single-loop coil}

Fig. 7 Principle of wireless signal coupling between two radiofrequency coils and its application to wireless active catheter visualization. a Loop surface coil that is connected to the radiofrequency receiver of the scanner. b Distal end of a catheter that is equipped with a closed-loop coil that is tuned to resonance with a capacitor. In the body coil (not shown) radiofrequency

properties and vessel accessibility. It was tracked using signal peaks at the side bands of an SSFP sequence with very low flip angles [40]. This passive approach on the one hand seems superior to those passive concepts tracking

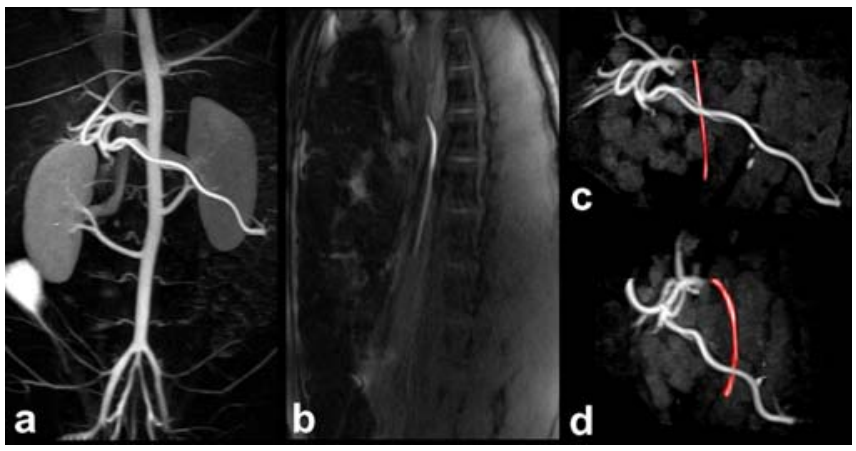

Fig. 8 a MIP of an MR angiogram acquired in the abdominal aorta of a pig following intra-venous contrast injection gives a comprehensive view of the vascular morphology. b The active wireless catheter has successfully been guided with real-time projection reconstruction TrueFISP imaging (one frame shown) into the celiac trunk. Images (c) and (d) show MIPs of selective time-resolved high-resolution 3D FLASH contrast-enhanced MRA of the celiac trunk with the SMA in a coronal (c) and in a sagittal (d) projection. Contrast agent was administered through the tip of the wireless active catheter. The distal active end of the catheter was coloured in red. Note excellent correlation between the intra-venous MR angiography in (a) and the intra-arterial MRA in (c) and (d). (Reproduced from Quick et al. [61]) transmit mode, the resonant catheter coil locally multiplies the excitation flip angle. In the radiofrequency receive mode, the resonant catheter coil picks up the MR signal in its immediate vicinity, resulting in a B1 field vector that can be inductively coupled to that of the loop surface coil (a). (Reproduced from Quick et al. [61])

pure signal voids, as a signal void may be averaged in a larger imaging slice and as other conditions may cause signal loss in MRI, as mentioned above Furthermore, compared with active devices, much less technical and regulatory requirements exist, as shown above.

In general, the critical features of guidewires are steerability, robustness and torque control. Fibreglass, for example, offers a good pushability, but is less resistant to torque and thus may fracture during an intervention. PEEK, on the other hand, is less rigid, thereby minimizing the risk of core fracture but offering less pushability. In our opinion, a compound solution with a fibreglass core and a PEEK surface may be the solution.

To our knowledge, the loopless antenna guidewire coil (Intercept; Surgi-Vision, Gaithersburg, Md.) used by Omary et al. [27], being 0.030 inch in diameter is the smallest guidewire for MR interventions available so far. As a mechanical hurdle until today, it was not shown that smaller MR guidwire diameters, such as 0.014 inch and

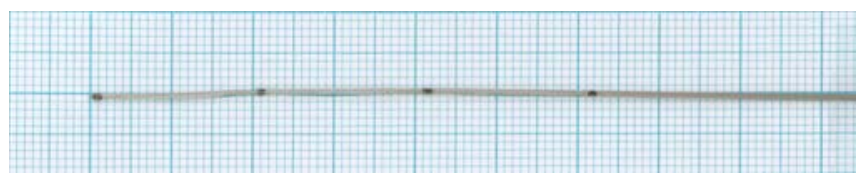

Fig. 9 Newly developed polyetherketone (PEEK) MR-compatible guidewire reinforced by a fibreglass compound. Metal rings are mounted on the tip. The total diameter is $0.035 \mathrm{in} / 0.85 \mathrm{~mm}$. This allows the use of conventional catheters over the wire 
0.018 inch, as used in cardiac and cerebrovascular interventions, may be produced with the attachments needed for MR tracking.

\section{Safety aspects}

Following the ALARA principle (as low as reasonable achievable) for the use of ionizing radiation, the use of MR guidance for interventional procedures should be favoured over X-ray fluoroscopy and CT. However, today's distribution of MR systems and the resulting costs make a reduction to special indications necessary. Primarily such patients should be in the focus for MR-guided interventions who undergo complex and long-lasting or redundant procedures, thereby increasing the risk for patient and staff to suffer from deterministic X-ray damage like erythema or hair loss. Also, young patients carrying the stochastic events of radiation exposure throughout their lifetimes should benefit from the use of MRI in procedure guidance.

Rapid heating of electrically conductive foreign bodies and instruments under radiofrequency energy excitation is a well-known problem. In 1.5-T fields, temperature changes of up to $44^{\circ} \mathrm{C}$ were observed [66, 67]. In vitro experiments with standard nitinol guidewires, which are not ferromegnatic but electrical conductors, showed substantial heating around the guidewire tips. The degree of heating is proportional to the power of the radiofrequency pulse. It also varies between different sequences and changes with the flip angle. Wildermuth et al. [68] found sequences with higher duty cyles, as fast spin echo sequences, and high flip angles $\left(90^{\circ}\right)$ in gradient-recall echo sequences to cause most wire heating $\left(18-20^{\circ} \mathrm{C}\right)$. However, studies using nitinol guidewires "off-label" did not show any harmful side effects caused by this heating in vivo, so its use is controversial [69]. The shown potential risks enforce the need for new MR-suitable instruments, e.g. the above-mentioned guidewires, replacing nitinol-based components, to make further discussion about the potential effects in vivo unnecessary. These tools will need comparable rigidity and torque responsiveness as their conventional counterparts, to prevent device fracture in vivo.

Further research will be needed to investigate the postulated effects of gadolinium-based contrast media on the pathogenesis of nephrogenic systemic fibrosis in patients with end-stage renal insufficiency [70].

Table 1 Synopsis of hallmarks in endovascular interventional MR, mentioning animal experiments and clinical studies

Synopsis of milestones in MR-guided vascular interventions

\begin{tabular}{|c|c|c|}
\hline Rubin et al. $[71]^{\mathrm{a}}$ & 1990 & Description of passive catheter tracking using susceptibility effects \\
\hline Dumoulin et al. $[48]^{\mathrm{a}}$ & 1993 & Description of active near real-time catheter tracking using radiofrequency coils \\
\hline Bakker et al. [20] & 1997 & First passive catheter tracking in human \\
\hline Wildermuth et al. [16] & 1997 & First MR-guided PTA (swine) \\
\hline Bücker et al. [72] & 1998 & Endovascular stent placement (swine) \\
\hline Kee et al. [81] & 1999 & TIPS placement (swine) \\
\hline Lardo et al. [73] & 2000 & Radiofrequency ablation of the heart (dog) \\
\hline Omary et al. [46] & 2000 & Angioplasty of renal artery stenoses (swine) \\
\hline Manke et al. [69] & 2000 & Stent placement in pelvic artery stenoses (human) \\
\hline Bücker et al. [83] & 2001 & Filter placement in the inferior vena cava (swine) \\
\hline Bücker et al. [78] & 2002 & Placement septal closure device (swine) \\
\hline Spüntrup et al. [79] & 2002 & Coronary artery stent placement (swine) \\
\hline Serfaty et al. [80] & 2003 & Coronary catheterization and PTCA (dog) \\
\hline Razavi et al. [12] & 2003 & Cardiac catheterization in children and adults with congenital heart disease (human) \\
\hline Bücker et al. [76] & 2003 & Coil-Embolisation of renal arteries (swine) \\
\hline Bock et al. $[54]^{\mathrm{a}}$ & 2004 & Real-Time parameter control and automated slice repositioning with active tracking coils \\
\hline Wacker et al. $[56]^{\mathrm{a}}$ & 2004 & The catheter driven MRI scanner \\
\hline Kühne et al. [84] & 2004 & Aortic valve positioning (swine) \\
\hline Mahnken et al. [82] & 2004 & Aortic stent graft placement (swine) \\
\hline Paetzel et al. [85] & 2004 & PTA of femoral and popliteal stenoses (human) \\
\hline Quick et al. [61] ${ }^{\mathrm{a}}$ & 2005 & Wireless active catheter visualization \\
\hline Mekle et al. $[40]^{\mathrm{a}}$ & 2006 & Description of the MR-compatible PEEK guidewire \\
\hline
\end{tabular}

${ }^{\mathrm{a}}$ As a backbone for temporal orientation, some relevant technical innovations are included. 


\section{In vivo applications}

Since the description of MR tracking techniques suitable for endovascular interventions, research has been performed showing feasibility in animal studies and consecutively demonstrating the possible clinical transfer (Table 1) $[48,71]$.

In 1997, the first human experiment described excellent MR visualization of a solid catheter with five integrated dysprosium rings [20]. Simple movements of the catheter in the cephalic vein were possible without a guidewire. In 1998, Bücker et al. [72] first showed the feasibility of MRguided stent placement. They successfully placed stents in porcine iliac arteries using radial scanning with a gradientecho sequence for guidance. In the meantime, it has been shown in other animal models that angioplasty, TIPS placement, stenting of aortic aneurysms, aortic dissections, pelvic, coronary and renal arteries and the inferior vena cava is as feasible as selective renal artery embolisation and occlusion of cardiac septal defects, prosthetic valve implantation and radiofrequency ablation under MR guidance (Fig. 10) [27, 46, 72-84]. First interventional procedures have been demonstrated in humans with conventional devices [85]. As pioneers, in 2000 Manke et al. [69] successfully performed MR-guided stent angioplasty of iliac artery stenoses using the passive tracking approach. In 2003, Razavi et. al. [12] were furthermore able to guide diagnostic or therapeutic cardiac catheterization in 14 patients with congenital heart disease. Krombach et al. [86] even used MRI to document the distribution of intramyocardially injected extracellular MR contrast medium (gadolinium-DTPA), which may be of use in the controlled and focal delivery of cardiac therapy under MR guidance, as described by Saeed et al. [87]. However, there is still a lack of certified MR tools, especially guidewires, that allow secure endovascular applications. After further development and certification, clinical trials on human application are recommended to demonstrate the benefit and possible superiority of MR-guided interventions over X-ray-guided intervention for clinical routine. In principle, there is no concern why vascular intervention, being conventionally performed so far, should not be feasible under MR guidance. It is also likely that the MR capability to even visualize functional parameters like flow, temperature, perfusion and diffusion will be used to directly monitor the outcome of interventions.

\section{Summary}

Within the last decade, tremendously increasing numbers of minimally invasive interventional procedures have been performed throughout the world. To broadly implement a novel image modality, like in this case MRI as a guidance procedure in daily practice, it will need further research to show its superiority towards existing modalities. This is especially demanding as the existing conventional systems

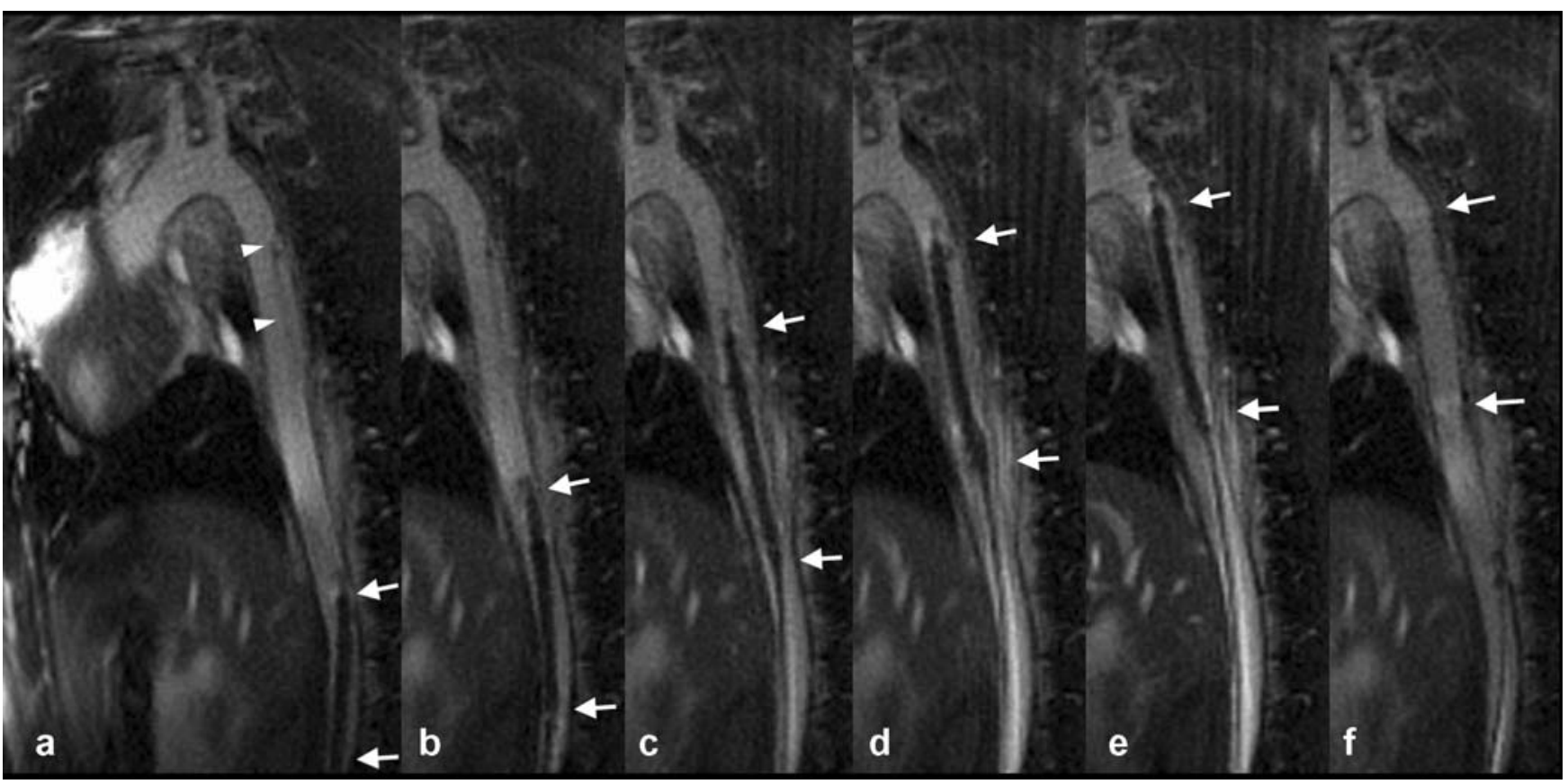

Fig. 10 Safe advancement of the stent-graft delivery system (arrows) up to the level of a dissection (arrowheads) under realtime MRI guidance (a-e). The correct stent-graft position (arrows) is confirmed immediately after stent-graft deployment showing complete coverage of the dissection (f). Real-time imaging was performed with an interactive projection reconstruction real-time TrueFISP sequence providing a reconstructed imaging rate of 7 frames/s at an imaging matrix of $192 \times 192$ pixel. (Reproduced from Eggebrecht et al. [75]) 
and techniques have been optimized for years, leading to a stable, robust, and for the interventionalist, convenient setup. IMRI therefore faces big challenges to guarantee the same comfort (e.g. patient accessibility, speed, interactive procedure control, less noise) and stability as conventional systems already guidance today.

It is very likely that unique features of MRI-like the use of non-nephrotoxic doses of contrast agents, the lack of ionizing radiation and its high contrast resolution, multiplanar 3D capabilities with arbitrary plane selection-and the ability to depict tissue composition and functional parameters-like flow, temperature, perfusion and diffusion-will allow this proof. To achieve this goal, interdisciplinary research and development regarding faster MR sequences, better MR systems, interactive visualization tools and new interventional and tracking devices, have to be performed. By that approach the still existing technical limitations and problems, as also discussed in this review, will certainly be resolved. Big steps have been made and a few devices are already close to certification, but in a second step the therapeutic impact and patient benefit must be proven, to justify the expectable costs.

\section{References}

1. Rhee TK, Larson AC, Prasad PV, Santos E, Sato KT, Salem R, Deng J, Paunesku T, Woloschak GE, Mulcahy MF, Li D, Omary RA (2005) Feasibility of blood oxygenation level-dependent MR imaging to monitor hepatic transcatheter arterial embolization in rabbits. J Vasc Interv Radiol 16:1523-1528

2. Wacker FK (2004) [Interventionel MRT: current inventory and preview]. Rofo 176:941-943

3. Ozturk C, Guttman M, McVeigh ER, Lederman RJ (2005) Magnetic resonance imaging-guided vascular interventions. Top Magn Reson Imaging 16:369-381

4. Wacker FK, Hillenbrand CM, Duerk JL, Lewin JS (2005) MR-guided endovascular interventions: device visualization, tracking, navigation, clinical applications, and safety aspects. Magn Reson Imaging Clin N Am 13:431-439

5. Schulz T, Puccini S, Schneider JP, Kahn T (2004) Interventional and intraoperative MR: review and update of techniques and clinical experience. Eur Radiol 14:2212-2227

6. Smits HF, Bos C, van der Weide R, Bakker CJ (1999) Interventional MR: vascular applications. Eur Radiol 9:1488-1495

7. Wacker FK, Bock M (2007) [Magnetic resonance imaging-guided endovascular interventions]. Rofo 179:355-364

8. Shellock FG, Crues JV (2004) MR procedures: biologic effects, safety, and patient care. Radiology 232:635-652

9. Silverman SG, Tuncali K, Morrison PR (2005) MR imaging-guided percutaneous tumor ablation. Acad Radiol 12:1100-1109
10. Wacker FK, Hillenbrand C, Elgort DR, Zhang S, Duerk JL, Lewin JS (2005) MR imaging-guided percutaneous angioplasty and stent placement in a swine model comparison of open- and closed-bore scanners. Acad Radiol 12:1085-1088

11. Buecker A, Spuentrup E, SchmitzRode T, Kinzel S, Pfeffer J, Hohl C, van Vaals JJ, Gunther RW (2004) Use of a nonmetallic guide wire for magnetic resonance-guided coronary artery catheterization. Invest Radiol 39:656660

12. Razavi R, Hill DL, Keevil SF, Miquel ME, Muthurangu V, Hegde S, Rhode K, Barnett M, van Vaals J, Hawkes DJ, Baker E (2003) Cardiac catheterisation guided by MRI in children and adults with congenital heart disease. Lancet 362:1877-1882

13. Dick AJ, Raman VK, Raval AN, Guttman MA, Thompson RB, Ozturk C, Peters DC, Stine AM, Wright VJ, Schenke WH, Lederman RJ (2005) Invasive human magnetic resonance imaging: feasibility during revascularization in a combined XMR suite. Catheter Cardiovasc Interv 64:265-274

14. Vogl TJ, Balzer JO, Mack MG, Bett G, Oppelt A (2002) Hybrid MR interventional imaging system: combined MR and angiography suites with single interactive table. Feasibility study in vascular liver tumor procedures. Eur Radiol 12:1394-1400

15. Fahrig R, Butts K, Rowlands JA, Saunders R, Stanton J, Stevens GM, Daniel BL, Wen Z, Ergun DL, Pelc NJ (2001) A truly hybrid interventional MR/X-ray system: feasibility demonstration. J Magn Reson Imaging 13:294-300

16. Wildermuth S, Debatin JF, Leung DA, Dumoulin CL, Darrow RD, Uhlschmid G, Hofmann E, Thyregod J, von Schulthess GK (1997) MR imagingguided intravascular procedures: initial demonstration in a pig model. Radiology 202:578-583
17. Huegli RW, Aschwanden M, Bongartz G, Jaeger K, Heidecker HG, Thalhammer C, Schulte AC, Hashagen C, Jacob AL, Bilecen D (2006) Intraarterial MR angiography and DSA in patients with peripheral arterial occlusive disease: prospective comparison. Radiology 239:901-908

18. Huegli RW, Aschwanden M, Scheffler K, Bilecen D (2006) Fluoroscopic contrast-enhanced MR angiography with a magnetization-prepared steadystate free precession technique in peripheral arterial occlusive disease. AJR Am J Roentgenol 187:242-247

19. Wyttenbach R, Gallino A, Alerci M, Mahler F, Cozzi L, Di Valentino M, Badimon JJ, Fuster V, Corti R (2004) Effects of percutaneous transluminal angioplasty and endovascular brachytherapy on vascular remodeling of human femoropopliteal artery by noninvasive magnetic resonance imaging. Circulation 110:1156-1161

20. Bakker CJ, Hoogeveen RM, Hurtak WF, van Vaals JJ, Viergever MA, Mali WP (1997) MR-guided endovascular interventions: susceptibility-based catheter and near-real-time imaging technique. Radiology 202:273-276

21. Bock M, Muller S, Zuehlsdorff S, Speier P, Fink C, Hallscheidt P, Umathum R, Semmler W (2006) Active catheter tracking using parallel MRI and real-time image reconstruction. Magn Reson Med 55:1454-1459

22. Zhang H, Maki JH, Prince MR (2007) 3D contrast-enhanced MR angiography. J Magn Reson Imaging 25:13-25

23. Potthast S, Schulte AC, Bongartz GM, Hugli R, Aschwanden M, Bilecen D (2005) Low-dose intra-arterial contrastenhanced MR aortography in patients based on a theoretically derived injection protocol. Eur Radiol 15:2347-2353

24. Lin SP, Brown JJ (2007) MR contrast agents: physical and pharmacologic basics. J Magn Reson Imaging 25:884-899 
25. Maes RM, Lewin JS, Duerk JL, Wacker FK (2005) Combined use of the intravascular blood-pool agent, gadomer, and carbon dioxide: a novel type of double-contrast magnetic resonance angiography (MRA). J Magn Reson Imaging 21:645-649

26. Goyen M, Shamsi K, Schoenberg SO (2006) Vasovist-enhanced MR angiography. Eur Radiol 16(Suppl 2):B9-14

27. Omary RA, Gehl JA, Schirf BE, Green JD, Lu B, Pereles FS, Huang J, Larson AC, Li D (2006) MR imaging- versus conventional X-ray fluoroscopy-guided renal angioplasty in swine: prospective randomized comparison. Radiology 238:489-496

28. Duerk JL, Butts K, Hwang KP, Lewin JS (2000) Pulse sequences for interventional magnetic resonance imaging. Top Magn Reson Imaging 11:147-162

29. Hennig J, Scheffler K, Laubenberger J, Strecker R (1997) Time-resolved projection angiography after bolus injection of contrast agent. Magn Reson Med 37:341-345

30. Wang Y, Johnston DL, Breen JF, Huston J 3rd, Jack CR, Julsrud PR, Kiely MJ, King BF, Riederer SL, Ehman RL (1996) Dynamic MR digital subtraction angiography using contrast enhancement, fast data acquisition, and complex subtraction. Magn Reson Med 36:551-556

31. Bos C, Bakker CJ, Viergever MA (2001) Background suppression using magnetization preparation for contrastenhanced MR projection angiography. Magn Reson Med 46:78-87

32. Quick HH, Kuehl H, Kaiser G, Hornscheidt D, Mikolajczyk KP, Aker S, Debatin JF, Ladd ME (2003) Interventional MRA using actively visualized catheters, TrueFISP, and real-time image fusion. Magn Reson Med 49:129-137

33. Kaul MG, Stork A, Bansmann PM, Nolte-Ernsting C, Lund GK, Weber C, Adam G (2004) Evaluation of balanced steady-state free precession (TrueFISP) and $\mathrm{K}$-space segmented gradient echo sequences for $3 \mathrm{D}$ coronary MR angiography with navigator gating at 3 Tesla. Rofo 176:1560-1565

34. Bieri O, Markl M, Scheffler K (2005) Analysis and compensation of eddy currents in balanced SSFP. Magn Reson Med 54:129-137

35. Griswold MA, Jakob PM, Heidemann RM, Nittka M, Jellus V, Wang J, Kiefer B, Haase A (2002) Generalized autocalibrating partially parallel acquisitions (GRAPPA). Magn Reson Med 47:1202-1210
36. van Vaals JJ, Brummer ME, Dixon WT, Tuithof HH, Engels H, Nelson RC, Gerety BM, Chezmar JL, den Boer JA (1993) "Keyhole" method for accelerating imaging of contrast agent uptake. J Magn Reson Imaging 3:671-675

37. Potthast S, Bongartz GM, Huegli R, Schulte AC, Schwarz JG, Aschwanden M, Bilecen D (2007) Intraarterial contrast-enhanced MR aortography with and without parallel acquisition technique in patients with peripheral arterial occlusive disease. AJR Am J Roentgenol 188:823-829

38. Araki T, Aoki S, Ishigame K, Kumagai H, Nanbu A, Hori M, Ueki J, Komiyama T, Araki T (2002) MRguided intravascular catheter manipulation: feasibility of both active and passive tracking in experimental study and initial clinical applications. Radiat Med 20:1-8

39. Unal O, Li J, Cheng W, Yu H, Strother CM (2006) MR-visible coatings for endovascular device visualization. J Magn Reson Imaging 23:763-769

40. Mekle R, Hofmann E, Scheffler K, Bilecen D (2006) A polymer-based MR-compatible guidewire: a study to explore new prospects for interventional peripheral magnetic resonance angiography (ipMRA). J Magn Reson Imaging 23:145-155

41. Bakker CJ, Hoogeveen RM, Weber J, van Vaals JJ, Viergever MA, Mali WP (1996) Visualization of dedicated catheters using fast scanning techniques with potential for MR-guided vascular interventions. Magn Reson Med 36:816-820

42. Bakker CJ, Bos C, Weinmann HJ (2001) Passive tracking of catheters and guidewires by contrast-enhanced MR fluoroscopy. Magn Reson Med 45:1723

43. Godart F, Beregi JP, Nicol L, Occelli B, Vincentelli A, Daanen V, Rey C, Rousseau J (2000) MR-guided balloon angioplasty of stenosed aorta: in vivo evaluation using near-standard instruments and a passive tracking technique. J Magn Reson Imaging 12:639-644

44. Ladd ME, Quick HH, Debatin JF (2000) Interventional MRA and intravascular imaging. J Magn Reson Imaging 12:534-546

45. Bakker CJ, Seppenwoolde JH, Bartels LW, van der Weide R (2004) Adaptive subtraction as an aid in MR-guided placement of catheters and guidewires. J Magn Reson Imaging 20:470-474

46. Omary RA, Frayne R, Unal O, Warner T, Korosec FR, Mistretta CA, Strother CM, Grist TM (2000) MR-guided angioplasty of renal artery stenosis in a pig model: a feasibility study. J Vasc Interv Radiol 11:373-381
47. Serfaty JM, Atalar E, Declerck J, Karmakar P, Quick HH, Shunk KA, Heldman AW, Yang X (2000) Real-time projection MR angiography: feasibility study. Radiology 217:290-295

48. Dumoulin CL, Souza SP, Darrow RD (1993) Real-time position monitoring of invasive devices using magnetic resonance. Magn Reson Med 29:411-415

49. Flask C, Elgort D, Wong E, Shankaranarayanan A, Lewin J, Wendt M, Duerk JL (2001) A method for fast 3D tracking using tuned fiducial markers and a limited projection reconstruction FISP (LPR-FISP) sequence. J Magn Reson Imaging 14:617-627

50. Burl M, Coutts GA, Young IR (1996) Tuned fiducial markers to identify body locations with minimal perturbation of tissue magnetization. Magn Reson Med 36:491-493

51. Wendt M, Busch M, Wetzler R, Zhang Q, Melzer A, Wacker F, Duerk JL, Lewin JS (1998) Shifted rotated keyhole imaging and active tip-tracking for interventional procedure guidance. J Magn Reson Imaging 8:258-261

52. Zuehlsdorff S, Umathum R, Volz S, Hallscheidt P, Fink C, Semmler W, Bock M (2004) MR coil design for simultaneous tip tracking and curvature delineation of a catheter. Magn Reson Med 52:214-218

53. Weiss S, Kuehne T, Brinkert F, Krombach G, Katoh M, Schaeffter T, Guenther RW, Buecker A (2004) In vivo safe catheter visualization and slice tracking using an optically detunable resonant marker. Magn Reson Med 52:860-868

54. Bock M, Volz S, Zuhlsdorff S, Umathum R, Fink C, Hallscheidt P, Semmler W (2004) MR-guided intravascular procedures: real-time parameter control and automated slice positioning with active tracking coils. J Magn Reson Imaging 19:580-589

55. Elgort DR, Wong EY, Hillenbrand CM, Wacker FK, Lewin JS, Duerk JL (2003) Real-time catheter tracking and adaptive imaging. J Magn Reson Imaging 18:621-626

56. Wacker FK, Elgort D, Hillenbrand CM, Duerk JL, Lewin JS (2004) The catheter-driven MRI scanner: a new approach to intravascular catheter tracking and imaging-parameter adjustment for interventional MRI. AJR Am J Roentgenol 183:391-395

57. Glowinski A, Adam G, Bucker A, Neuerburg J, van Vaals JJ, Gunther RW (1997) Catheter visualization using locally induced, actively controlled field inhomogeneities. Magn Reson Med 38:253-258 
58. Weiss S, Vernickel P, Schaeffter T, Schulz V, Gleich B (2005) Transmission line for improved RF safety of interventional devices. Magn Reson Med 54:182-189

59. Ladd ME, Quick HH (2000) Reduction of resonant RF heating in intravascular catheters using coaxial chokes. Magn Reson Med 43:615-619

60. Buecker A, Adam GB, Neuerburg JM, Kinzel S, Glowinski A, Schaeffter T, Rasche V, van Vaals JJ, Guenther RW (2002) Simultaneous real-time visualization of the catheter tip and vascular anatomy for MR-guided PTA of iliac arteries in an animal model. J Magn Reson Imaging 16:201-208

61. Quick HH, Zenge MO, Kuehl H, Kaiser G, Aker S, Massing S, Bosk S, Ladd ME (2005) Interventional magnetic resonance angiography with no strings attached: wireless active catheter visualization. Magn Reson Med 53:446-455

62. Wong EY, Zhang Q, Duerk JL, Lewin JS, Wendt M (2000) An optical system for wireless detuning of parallel resonant circuits. J Magn Reson Imaging 12:632-638

63. Bock M, Umathum R, Sikora J, Brenner S, Aguor EN, Semmler W (2006) A Faraday effect position sensor for interventional magnetic resonance imaging. Phys Med Biol 51:999-1009

64. Scheffler K, Korvink JG (2004) Navigation with Hall sensor device for interventional MRI. In: Proceedings of the 12th Annual Meeting of ISMRM, Kyoto,, 2004, p 950

65. Bakker CJ, Smits HF, Bos C, van der Weide R, Zuiderveld KJ, van Vaals JJ, Hurtak WF, Viergever MA, Mali WP (1998) MR-guided balloon angioplasty: in vitro demonstration of the potential of MRI for guiding, monitoring, and evaluating endovascular interventions. J Magn Reson Imaging 8:245-250

66. Liu CY, Farahani K, Lu DS, Duckwiler G, Oppelt A (2000) Safety of MRIguided endovascular guidewire applications. J Magn Reson Imaging 12:75-78

67. Nitz WR, Oppelt A, Renz W, Manke C, Lenhart M, Link J (2001) On the heating of linear conductive structures as guide wires and catheters in interventional MRI. J Magn Reson Imaging 13:105-114

68. Wildermuth S, Dumoulin CL, Pfammatter T, Maier SE, Hofmann E, Debatin JF (1998) MR-guided percutaneous angioplasty: assessment of tracking safety, catheter handling and functionality. Cardiovasc Intervent Radiol 21:404-410
69. Manke C, Nitz WR, Lenhart M, Volk M, Geissler A, Djavidani B, Strotzer M, Kasprzak P, Feuerbach S, Link J (2000) [Stent angioplasty of pelvic artery stenosis with MRI control: initial clinical results]. Rofo 172:92-97

70. Thomsen HS (2006) Nephrogenic systemic fibrosis: a serious late adverse reaction to gadodiamide. Eur Radiol 16:2619-2621

71. Rubin DL, Ratner AV, Young SW (1990) Magnetic susceptibility effects and their application in the development of new ferromagnetic catheters for magnetic resonance imaging. Invest Radiol 25:1325-1332

72. Bucker A, Neuerburg JM, Adam G, Schurmann K, Rasche V, van Vaals JJ, Molgaard-Nielsen A, Gunther RW (1998) [Stent placement with real time MRI guidance: initial animal experiment experiences]. Rofo 169:655-657

73. Lardo AC, McVeigh ER, Jumrussirikul P, Berger RD, Calkins H, Lima J, Halperin HR (2000) Visualization and temporal/spatial characterization of cardiac radiofrequency ablation lesions using magnetic resonance imaging. Circulation 102:698-705

74. Wacker FK, Reither K, Ebert W, Wendt M, Lewin JS, Wolf KJ (2003) MR image-guided endovascular procedures with the ultrasmall superparamagnetic iron oxide SH U 555 C as an intravascular contrast agent: study in pigs. Radiology 226:459-464

75. Eggebrecht H, Kuhl H, Kaiser GM, Aker S, Zenge MO, Stock F, Breuckmann F, Grabellus F, Ladd ME, Mehta RH, Erbel R, Quick HH (2006) Feasibility of real-time magnetic resonance-guided stent-graft placement in a swine model of descending aortic dissection.

Eur Heart J 27:613-620

76. Bucker A, Neuerburg JM, Adam G, Glowinski A, van Vaals JJ, Gunther RW (2003) [MR-guided coil embolisation of renal arteries in an animal model]. Rofo 175:271-274

77. Fink C, Bock M, Umathum R, Volz S, Zuehlsdorff S, Grobholz R, Kauczor HU, Hallscheidt P (2004) Renal embolization: feasibility of magnetic resonance-guidance using active catheter tracking and intraarterial magnetic resonance angiography. Invest Radiol 39:111-119

78. Buecker A, Spuentrup E, Grabitz R, Freudenthal F, Muehler EG, Schaeffter T, van Vaals JJ, Gunther RW (2002) Magnetic resonance-guided placement of atrial septal closure device in animal model of patent foramen ovale. Circulation 106:511-515
79. Spuentrup E, Ruebben A, Schaeffter T, Manning WJ, Gunther RW, Buecker A (2002) Magnetic resonance-guided coronary artery stent placement in a swine model. Circulation 105:874-879

80. Serfaty JM, Yang X, Foo TK, Kumar A, Derbyshire A, Atalar E (2003) MRIguided coronary catheterization and PTCA: a feasibility study on a dog model. Magn Reson Med 49:258-263

81. Kee ST, Rhee JS, Butts K, Daniel B, Pauly J, Kerr A, O’Sullivan GJ, Sze DY, Razavi MK, Semba CP, Herfkens RJ, Dake MD (1999) 1999 Gary J. Becker Young Investigator Award. MR-guided transjugular portosystemic shunt placement in a swine model. J Vasc Interv Radiol 10:529-535

82. Mahnken AH, Chalabi K, Jalali F, Gunther RW, Buecker A (2004) Magnetic resonance-guided placement of aortic stents grafts: feasibility with realtime magnetic resonance fluoroscopy. J Vasc Interv Radiol 15:189-195

83. Bucker A, Neuerburg JM, Adam GB, Glowinski A, Schaeffter T, Rasche V, van Vaals JJ, Gunther RW (2001) Realtime MR Guidance for inferior vena cava filter placement in an animal model. J Vasc Interv Radiol 12: 753-756

84. Kuehne T, Yilmaz S, Meinus C, Moore P, Saeed M, Weber O, Higgins CB, Blank T, Elsaesser E, Schnackenburg B, Ewert P, Lange PE, Nagel E (2004) Magnetic resonance imaging-guided transcatheter implantation of a prosthetic valve in aortic valve position: feasibility study in swine. J Am Coll Cardiol 44:2247-2249

85. Paetzel C, Zorger N, Bachthaler M, Hamer OW, Stehr A, Feuerbach S, Lenhart M, Volk M, Herold T, Kasprzak P, Nitz WR (2005) Magnetic resonance-guided percutaneous angioplasty of femoral and popliteal artery stenoses using real-time imaging and intra-arterial contrast-enhanced magnetic resonance angiography. Invest Radiol 40:257-262

86. Krombach GA, Baireuther R, Higgins CB, Saeed M (2004) Distribution of intramyocardially injected extracellular MR contrast medium: effects of concentration and volume. Eur Radiol 14:334-340

87. Saeed M, Saloner D, Weber O, Martin A, Henk C, Higgins C (2005) MRI in guiding and assessing intramyocardial therapy. Eur Radiol 15:851-863 